Check for updates

Cite this: RSC Adv., 2017, 7, 18690

Received 6th March 2017

Accepted 22nd March 2017

DOI: $10.1039 / c 7 r a 02699 d$

rsc.li/rsc-advances

\section{Singlet oxygen generation properties of an inclusion complex of cyclic free-base porphyrin dimer and fullerene $\mathrm{C}_{60}{ }^{\dagger}$}

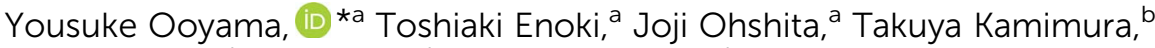 \\ Shuwa Ozako, ${ }^{\mathrm{b}}$ Taro Koide ${ }^{\mathrm{b}}$ and Fumito Tani ${ }^{\star b}$
}

To gain insight into the singlet oxygen $\left({ }^{1} \mathrm{O}_{2}\right)$ generation properties of supramolecular complexes of cyclic free-base porphyrin dimer with fullerene $\mathrm{C}_{60}$, we evaluated the ${ }^{1} \mathrm{O}_{2}$ quantum yield $\left(\Phi_{\Delta}\right)$ and rate constant $\left(K_{\text {obs }}\right)$ of ${ }^{1} \mathrm{O}_{2}$ generation for a cyclic free-base porphyrin dimer (CPD) linked by butadiyne bearing four 4pyridyl groups and its inclusion complex $\left(\mathrm{C}_{60} \subset \mathrm{CPD}\right)$ with $\mathrm{C}_{60}$. We demonstrate that $\mathrm{CPD}$ and $\mathrm{C}_{60} \subset \mathrm{CPD}$ possess the ability to generate ${ }^{1} \mathrm{O}_{2}$ under visible light irradiation. Moreover, it was found that the $\Phi_{\Delta}$ value of $\mathrm{C}_{60} \subset \mathrm{CPD}$ is lower than that of CPD. Based on the kinetic and thermodynamic consideration concerning the electron transfer processes between the porphyrin dimer and $C_{60}$, this work revealed that the lower $\Phi_{\Delta}$ value of the $C_{60}$ inclusion complex would be attributed to the formation of the charge-separated state $\mathrm{C}_{60}{ }^{--}-\mathrm{CPD}^{+}$, leading to a low intersystem crossing (ISC) efficiency for the formation of the triplet excited state ${ }^{3}(\mathrm{CPD}) *$.

\section{Introduction}

Photosensitizers possessing the ability to generate singlet oxygen $\left({ }^{1} \mathrm{O}_{2}\right)$ have created considerable interest in recent years from the viewpoint of fundamental studies in photochemistry and their potential applications in photodynamic therapy (PDT). ${ }^{1-6}$ These photosensitizers generally produce ${ }^{1} \mathrm{O}_{2}$ through the following processes: initially the photosensitizer absorbs light $(h \nu)$ to generate the singlet excited state of the photosensitizer $\left({ }^{1} S^{*}\right)$, then the photoexcited sensitizer $\left({ }^{1} S^{*}\right)$ undergoes intersystem crossing (ISC) to generate the triplet excited state $\left({ }^{3} \mathrm{~S}^{*}\right)$. Subsequent energy transfer from the photoexcited sensitizer $\left({ }^{3} \mathrm{~S}^{*}\right)$ to triplet oxygen $\left({ }^{3} \mathrm{O}_{2}\right)$ produces ${ }^{1} \mathrm{O}_{2}$. Thus, to generate ${ }^{3} \mathrm{~S}^{*}$ efficiency is one of the most effective strategies to give high ${ }^{1} \mathrm{O}_{2}$ quantum yield $\left(\Phi_{\Delta}\right)$. In particular, porphyrin dyes have been regarded as promising candidates for photosensitizers as a result of their strong Soret (400-500 nm) and moderate Q band (500-700 nm) absorption properties, as well as their electrochemical, photochemical and thermal stabilities. The typical photosensitizer, free-base tetraphenylporphyrin $\left(\mathrm{H}_{2} \mathrm{TPP}\right)$ exhibits $\Phi_{\Delta}$ value of $0.6-0.7$ (in benzene). ${ }^{7}$ Much effort in

${ }^{a}$ Department of Applied Chemistry, Graduate School of Engineering, Hiroshima University, Higashi-Hiroshima 739-8527, Japan. E-mail: yooyama@hiroshima-u.ac. jp; Fax: +81-82-424-5494

${ }^{b}$ Institute for Materials Chemistry and Engineering, Kyushu University, 744 Motooka, Nishi-ku, Fukuoka 819-0395, Japan. E-mail: tanif@ms.ifoc.kyushu-u.ac.jp; Fax: +8192-802-6224

$\dagger$ Electronic supplementary information (ESI) available. See DOI: 10.1039/c7ra02699d molecular design and development of porphyrin photosensitizers have been made to further improve the $\Phi_{\Delta}$ value so far..$^{7-11}$ Some researchers reported that porphyrin-fullerene $\mathrm{C}_{60}$ dyads as well as boron dipyrromethene (BODIPY)- $\mathrm{C}_{60}$ dyads exhibits a higher $\Phi_{\Delta}$ value than each porphyrin or $\mathrm{C}_{60}$, which is attributed to the formation of long-lived triplet excited state $\left({ }^{3} \mathrm{~S}^{*}\right)$ by the effective ISC due to intramolecular energy transfer or
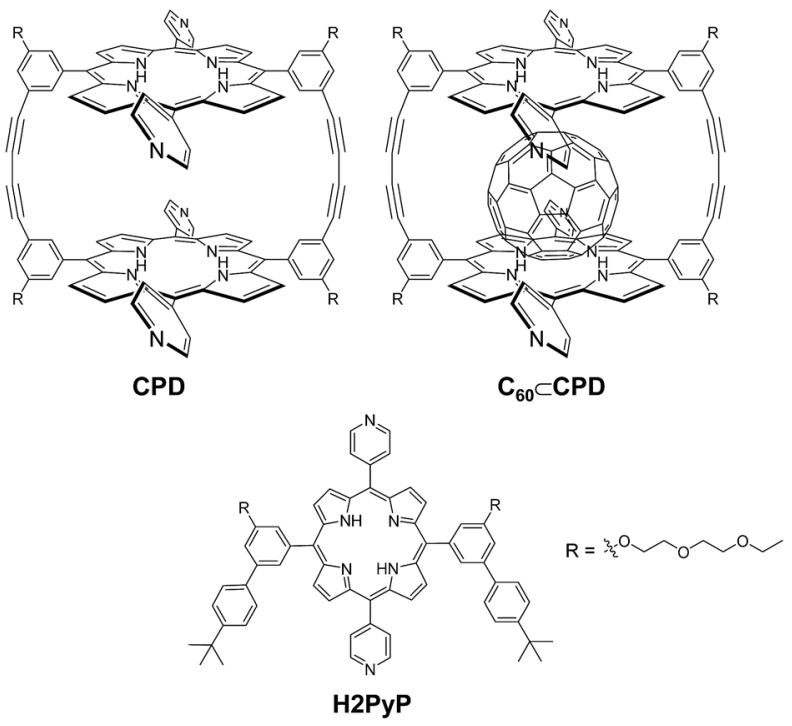

Fig. 1 Chemical structures of cyclic free-base porphyrin dimer (CPD) linked by butadiyne bearing four 4-pyridyl groups, its inclusion complex $\left(\mathrm{C}_{60} \subset \mathrm{CPD}\right)$ with $\mathrm{C}_{60}$ and $\mathrm{ABAB}$ porphyrin monomer H2PyP as a reference. 
electron transfer (charge separation) between photosensitizer and $\mathrm{C}_{60} \cdot{ }^{11,12}$

Recently, we have designed and developed cyclic free-base porphyrin dimer CPD linked by butadiyne bearing four 4-pyridyl groups and its inclusion complex $\mathbf{C}_{60} \subset \mathbf{C P D}$ with $\mathrm{C}_{60}$ (Fig. 1). ${ }^{13}$ It was expected that $\mathbf{C}_{60} \subset \mathbf{C P D}$ has favorable photochemical and electrochemical properties for PDT through the electrochemical measurements and the transient absorption spectroscopy, based on the fact that the singlet excited state $\left.\mathbf{C}_{60^{-}}{ }^{-1} \mathbf{C P D}\right)^{*}$ undergoes intrasupramolecular electron transfer to give a completely charge-separated state $\mathbf{C}_{\mathbf{6 0}}{ }^{-{ }^{-}} \mathbf{C P D}^{+{ }^{+}}$. Thus, in this work, to gain insight into the ${ }^{1} \mathrm{O}_{2}$ generation properties of supramolecular complex of cyclic free-base porphyrin dimer with $\mathrm{C}_{60}$, we evaluated the $\Phi_{\Delta}$ and rate constant $\left(K_{\mathrm{obs}}\right)$ of ${ }^{1} \mathrm{O}_{2}$ generation for $\mathbf{C P D}$ and $\mathbf{C}_{60} \subset \mathbf{C P D}$. Here we reveal that cyclic free-base porphyrin dimer and its inclusion complex with fullerene $\mathrm{C}_{60}$ possess the ability to generate ${ }^{1} \mathrm{O}_{2}$ under visible light irradiation, based on the kinetic and thermodynamic consideration concerning the electron transfer processes between the porphyrin dimer and $\mathrm{C}_{60}$.

\section{Results and discussion}

The cyclic free-base porphyrin dimer $\mathbf{C P D}$ in $\mathrm{CH}_{2} \mathrm{Cl}_{2} / \mathrm{MeOH}$ exhibits strong Soret band at around $420 \mathrm{~nm}$ and relatively weak $\mathrm{Q}$ band in the range 500-650 $\mathrm{nm}$ (Fig. 2, $\lambda_{\max }^{\text {abs }} / \mathrm{nm}\left(\varepsilon / \mathrm{M}^{-1} \mathrm{~cm}^{-1}\right)=$ 416 (708 000), 514 (31 200), 548 (7400), 587 (9000), 642 (2900)). The molar extinction coefficients $(\varepsilon)$ of Soret and Q bands for CPD are higher than those of $\mathbf{H 2 P y P}\left(\lambda_{\max }^{\text {abs }} / \mathrm{nm}\left(\varepsilon / \mathbf{M}^{-1} \mathrm{~cm}^{-1}\right)=\right.$ 418 (419 000), 513 (19 200), 548 (6200), 588 (6000), 643 (3000)) ${ }^{13 e}$ as an $\mathrm{ABAB}$ porphyrin monomer with two pyridyl groups and two phenyl groups. The fact is attributed to the porphyrin dimer structure of CPD with two porphyrin units. For the $\mathrm{C}_{60}$ inclusion complex $\mathbf{C}_{60} \subset \mathbf{C P D}$, it is difficult to obtain its exact absorption spectra because the $1: 1$ complex of CPD with $\mathrm{C}_{60}$ is in dissociation equilibrium in solution of $10^{-5}$ to $10^{-6} \mathrm{M}$ concentration which is suitable for the measurement of photoabsorption spectra of porphyrins. In our previous work, however, we have demonstrated that upon addition of $\mathrm{C}_{60}$ to the solution of the cyclic porphyrin dimer, its Soret band was redshifted with a decrease in intensity, whereas its $\mathrm{Q}$ band was slightly redshifted but increased in intensity. ${ }^{13} \mathrm{O}_{2}$ generation by $\mathbf{C P D}, \mathbf{C}_{60} \subset \mathbf{C P D}$ or H2PyP in $\mathrm{CH}_{2} \mathrm{Cl}_{2} / \mathrm{MeOH}(=1 / 1, \mathrm{v} / \mathrm{v})$ was evaluated by monitoring

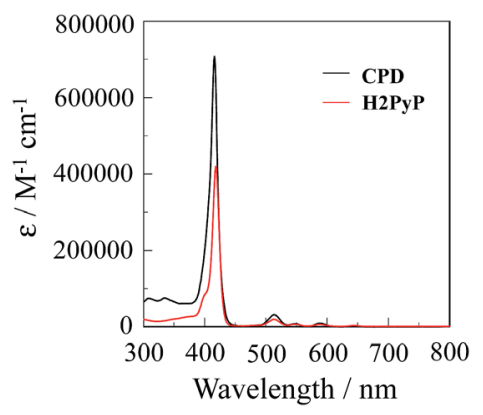

Fig. 2 Photoabsorption spectra of CPD and $\mathrm{H} 2 \mathrm{PyP}$ in $\mathrm{CH}_{2} \mathrm{Cl}_{2} / \mathrm{MeOH}$. the photoabsorption spectral change of the known ${ }^{1} \mathrm{O}_{2}$ scavenger 1,3-diphenylisobenzofuran (DPBF) accompanied by the reaction of DPBF with the generated ${ }^{1} \mathrm{O}_{2}$, that is, DPBF can trap ${ }^{1} \mathrm{O}_{2}$ through its photooxidation. $.^{14} \mathrm{CH}_{2} \mathrm{Cl}_{2} / \mathrm{MeOH}$ was bubbled with air for $15 \mathrm{~min}$. The air-saturated solution containing CPD, $\mathbf{C}_{60} \subset \mathbf{C P D}$ or H2PyP and DPBF was irradiated with $509 \mathrm{~nm}(300$ $\mu \mathrm{W} \mathrm{cm}{ }^{-2}, \varepsilon=27300 \mathrm{M}^{-1} \mathrm{~cm}^{-1} @ \lambda^{\mathrm{abs}}=509 \mathrm{~nm}$ for CPD and $\varepsilon=$ $17000 \mathrm{M}^{-1} \mathrm{~cm}^{-1} @ \lambda^{\text {abs }}=509 \mathrm{~nm}$ for H2PyP, respectively) obtained by passage of xenon light through monochromator. For both CPD and $\mathbf{C}_{60} \subset \mathbf{C P D}$ as well as H2PyP the absorption band of DPBF at around $410 \mathrm{~nm}$ decreased with the increase in the photoirradiation time (Fig. 3), which indicate the reaction of DPBF with ${ }^{1} \mathrm{O}_{2}$ generated upon the excitation of the porphyrin dimer. To gain insight into the effect of the cyclic porphyrin dimers on the efficiency of DPBF photooxidation, the changes in optical density $(\triangle \mathrm{OD})$ of DPBF are plotted against the photoirradiation time (Fig. 4a), and the slope $\left(m_{\mathrm{sl}}\right)$ is used to estimate the $\Phi_{\Delta}$ value for $\mathbf{C P D}, \mathbf{C}_{60} \subset \mathbf{C P D}$ and $\mathbf{H 2 P y P}$. The $m_{\mathrm{sl}}$ value $(-1.5$ $\left.\times 10^{-2}\right)$ of H2PyP is larger than those of CPD $\left(-1.2 \times 10^{-2}\right)$ and $\mathbf{C}_{60} \subset \mathbf{C P D}\left(-9.8 \times 10^{-3}\right)$. Moreover, it was revealed that the $m_{\mathrm{sl}}$ value of CPD is larger than that of $\mathbf{C}_{\mathbf{6 0}} \subset \mathbf{C P D}$. Thus, the $\Phi_{\Delta}$ values of $\mathbf{C P D}, \mathbf{C}_{60} \subset \mathbf{C P D}$ and $\mathbf{H 2 P y P}$ were estimated by the relative method using Rose Bengal (RB) $\left(\Phi_{\Delta}=0.80, m_{\mathrm{sl}}=-1.5 \times 10^{-2}\right.$, see Fig. S1 $\dagger$ ) in methanol ${ }^{15}$ as the standard (Table 1). The $\Phi_{\Delta}$ value of $\mathbf{C P D}, \mathbf{C}_{60} \subset \mathbf{C P D}$ and $\mathbf{H} 2 \mathrm{PyP}$ is $0.62,0.52$ and 0.91 respectively, which is in good agreement with the $m_{\mathrm{sl}}$ value. This result suggests that as for the $\mathrm{ABAB}$ porphyrin monomer $\mathbf{H 2 P y P}$ the ISC efficiency from ${ }^{1} \mathrm{~S}^{*}$ to the ${ }^{3} \mathrm{~S}^{*}$ may be higher than in the cyclic free-base porphyrin dimer CPD. Moreover, it is worth noting that the $\Phi_{\Delta}$ value of $\mathbf{C}_{\mathbf{6 0}} \subset \mathbf{C P D}$ is lower than that of CPD. Our previous work demonstrates that the decay of photoexcited
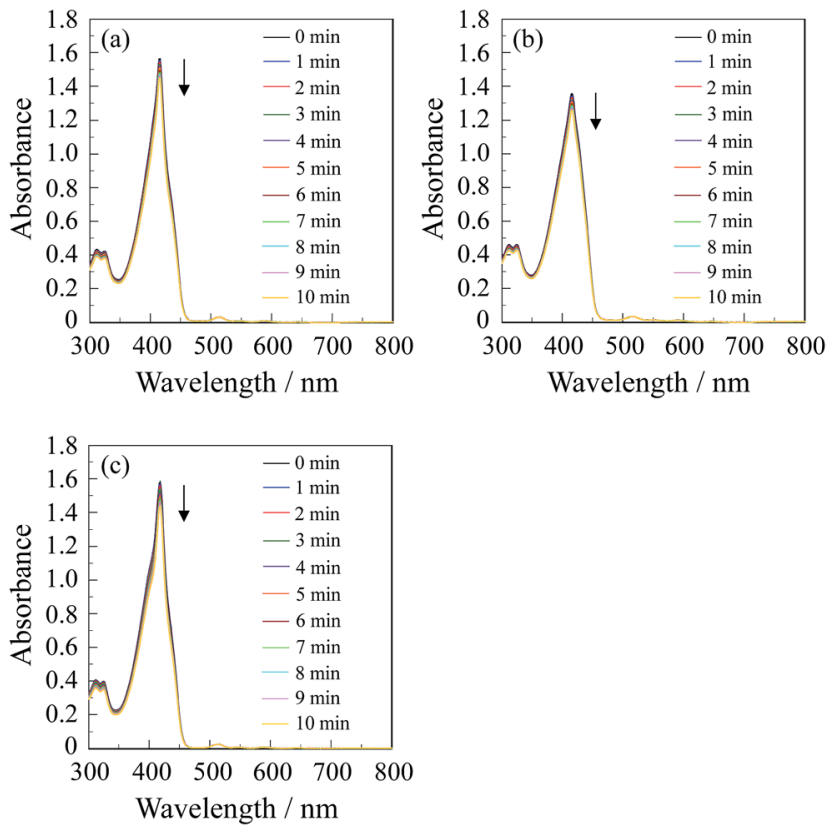

Fig. 3 Photoabsorption spectral changes for the photooxidation of DPBF (Abs. = ca. 1.0) using (a) CPD $\left(1.3 \times 10^{-6} \mathrm{M}\right)$, (b) $\mathrm{C}_{60} \subset \mathrm{CPD}(1.0 \times$ $\left.10^{-6} \mathrm{M}\right)$ and (c) H2PyP $\left(1.4 \times 10^{-6} \mathrm{M}\right)$ as photosensitizer under photoirradiation with $509 \mathrm{~nm}\left(300 \mu \mathrm{W} \mathrm{cm}{ }^{-2}\right)$ in $\mathrm{CH}_{2} \mathrm{Cl}_{2} / \mathrm{MeOH}(=1 / 1, \mathrm{v} / \mathrm{v})$. 

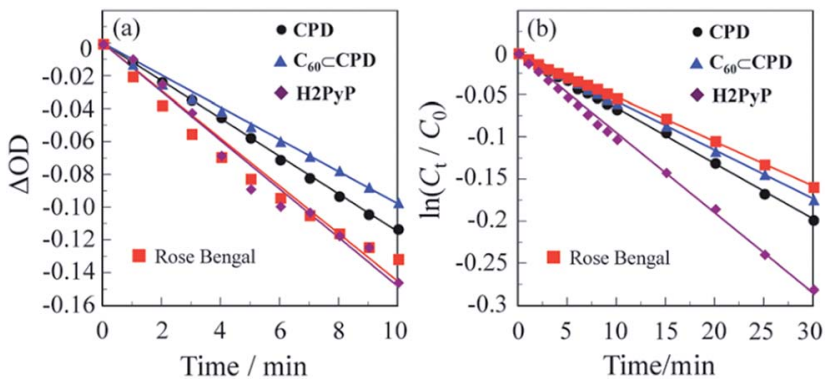

Fig. 4 (a) Plots of $\triangle O D$ for DPBF against the photoirradiation time for the photooxidation of DPBF using CPD, $\mathrm{C}_{60} \subset \mathrm{CPD}, \mathrm{H} 2 \mathrm{PyP}$ or Rose Bengal as photosensitizers under photoirradiation with $509 \mathrm{~nm}(300$ $\mu \mathrm{W} \mathrm{cm}{ }^{-2}$ ) in $\mathrm{CH}_{2} \mathrm{Cl}_{2} / \mathrm{MeOH}(=1 / 1, \mathrm{v} / \mathrm{v})$ and $\mathrm{MeOH}$, respectively. (b) Plots of $\ln \left(C_{t} / C_{0}\right)$ for $\mathrm{DHN}$ against the photoirradiation time for the photooxidation of DHN using CPD, $\mathrm{C}_{60} \subset \mathrm{CPD}, \mathrm{H} 2 \mathrm{PyP}$ or Rose Bengal as photosensitizers under photoirradiation with visible light $(>385 \mathrm{~nm}$, $30 \mathrm{~mW} \mathrm{~cm}^{-2}$ ) in $\mathrm{CH}_{2} \mathrm{Cl}_{2} / \mathrm{MeOH}(=1 / 1, \mathrm{v} / \mathrm{v})$.

Table $1{ }^{1} \mathrm{O}_{2}$ quantum yield $\left(\Phi_{\Delta}\right)$ and first-order rate constant $\left(K_{\text {obs }}\right)$ for the photooxidation of DPBF and DHN in $\mathrm{CH}_{2} \mathrm{Cl}_{2} / \mathrm{MeOH}(=1 / 1, \mathrm{v} / \mathrm{v})$, respectively, using $\mathrm{CPD}, \mathrm{C}_{60} \subset \mathrm{CPD}$ or $\mathrm{H} 2 \mathrm{PyP}$ as photosensitizer

\begin{tabular}{lcc}
\hline Photosensitizer & $\Phi_{\Delta}{ }^{a}$ & $K_{\text {obs }}{ }^{b} / \mathrm{min}^{-1}$ \\
\hline CPD & 0.62 & $6.6 \times 10^{-3}$ \\
C $_{60} \subset$ CPD & 0.52 & $5.8 \times 10^{-3}$ \\
H2PyP & 0.91 & $9.5 \times 10^{-3}$
\end{tabular}

${ }^{a}{ }^{1} \mathrm{O}_{2}$ quantum yield (relative decomposition rate of DPBF), with Rose Bengal (RB) as standard $\left(\Phi_{\Delta}=0.80\right.$ in methanol, ${ }^{15}$ see Fig. S1) and 3diphenylisobenzofuran (DPBF) as ${ }^{1} \mathrm{O}_{2}$ scavenger. ${ }^{b}$ First-order rate constant for the reaction of DHN with ${ }^{1} \mathrm{O}_{2}$ generated upon photoexcitation of the photosensitizer. The $K_{\mathrm{obs}}$ for $\mathrm{RB}$ is $5.3 \times 10^{-3}$ $\min ^{-1}$ (see Fig. S2).

state of $\mathbf{C}_{\mathbf{6 0}} \subset \mathbf{C P D}$ has two steps (Fig. 5): the first step has a lifetime of $18 \mathrm{ps}$, which corresponds to the disappearance of the singlet excited state of $\mathbf{C}_{60}{ }^{-1}(\mathbf{C P D})^{*}(c a .-3.6 \mathrm{eV})$, that is, $\mathrm{C}_{60}{ }^{-1}(\mathbf{C P D})^{*}$ undergoes intrasupramolecular electron transfer to give a completely charge-separated state $\mathbf{C}_{6 \mathbf{6 0}}{ }^{-{ }^{-}} \mathbf{C P D}^{+{ }^{+}}(\mathrm{ca} .-3.7$ $\mathrm{eV}){ }^{13} \mathbf{C}_{\mathbf{6 0}}{ }^{-{ }^{-}} \mathbf{C P D}^{+}$decays with a lifetime of $470 \mathrm{ps}$ to the ground state. The singlet excited state $\mathbf{C}_{\mathbf{6 0}}{ }^{-1}(\mathbf{C P D})^{*}$ has a slower ISC to its triplet excited state $\mathbf{C}_{60}{ }^{-3}(\mathbf{C P D})^{*}(c a .-4.0 \mathrm{eV})$, in addition, the $\mathbf{C}_{60^{-}}{ }^{3}(\mathbf{C P D})^{*}$ would undergo energy transfer to $\mathrm{C}_{60}$, leading to the

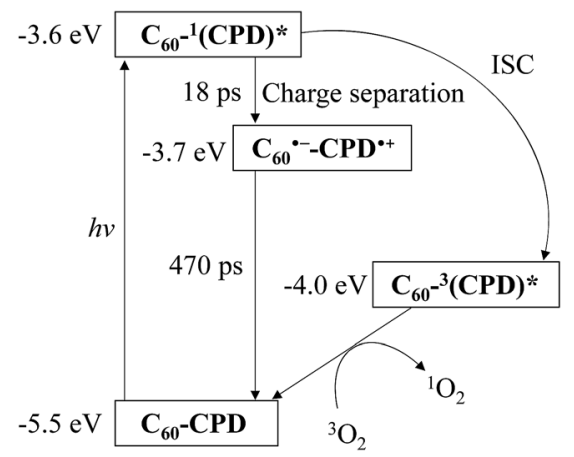

Fig. 5 The photodynamics of $\mathrm{C}_{60} \subset \mathrm{CPD}$ and ${ }^{1} \mathrm{O}_{2}$ generation. formation of ${ }^{3} \mathbf{C}_{60}{ }^{*}$-(CPD). Thus, on the basis of the photodynamics of the cyclic free-base porphyrin dimer and its inclusion complex with $\mathrm{C}_{60}$, the lower $\Phi_{\Delta}$ value of the $\mathrm{C}_{60}$ inclusion complex would be attributed to the formation of chargeseparated state, leading to low ISC efficiency because the ISC is in kinetically competition with the intrasupramolecular electron transfer, that is, the formation of triplet excited state $\left.{ }^{3} \mathbf{C P D}\right)^{*}$ is in kinetically unfavorable compared to that of the chargeseparated state $\mathbf{C}_{\mathbf{6 0}}{ }^{-{ }^{-}} \mathbf{C P D}^{+{ }^{+}}$.

In order to evaluate the photosensitizing ability of the cyclic free-base porphyrin dimer and its inclusion complex with $\mathrm{C}_{60}$, the $\ln \left(C_{t} / C_{0}\right)$ is plotted against the photoirradiation time, where $C_{t}$ is a concentration of 1,5-dihydroxynaphthalene (DHN) at the reaction time $(t)$ and $C_{0}$ is the initial concentration of DHN before photoirradiation. $\mathrm{CH}_{2} \mathrm{Cl}_{2} / \mathrm{MeOH}(=1 / 1, \mathrm{v} / \mathrm{v})$ were bubbled with air for $15 \mathrm{~min}$. The air-saturated solution containing $\mathbf{C P D}$ or $\mathbf{C}_{\mathbf{6 0}} \subset \mathbf{C P D}$ and DHN was irradiated with visible light ( $>385 \mathrm{~nm}, 30 \mathrm{~mW} \mathrm{~cm}{ }^{-2}$ ) obtained by passage of xenon light through a $385 \mathrm{~nm}$ long path filter. The photoabsorption spectral changes for the photooxidation of DHN using CPD, $\mathbf{C}_{60} \subset \mathbf{C P D}$ or H2PyP under photoirradiation with the visible light in $\mathrm{CH}_{2} \mathrm{Cl}_{2} / \mathrm{MeOH}(=1 / 1, \mathrm{v} / \mathrm{v})$ are shown in Fig. 6 . Evidently, the absorption band of DHN at around $300 \mathrm{~nm}$ decreased with the increase in the photoirradiation time. The plots of $\ln \left(C_{t} / C_{0}\right)$ against the photoirradiation time indicate that for CPD, $\mathbf{C}_{60} \subset \mathbf{C P D}$ and $\mathbf{H 2 P y P}$ the $\ln \left(C_{t} / C_{0}\right)$ decreased almost linearly with the increase in the photoirradiation time (Fig. 4b). Thus, this result indicates the $\ln \left(C_{t} / C_{0}\right)$ bears a linear relationship with the photoirradiation time to provide the first-order rate constants $\left(K_{\text {obs }}\right)$ for the photooxidation of DHN using the cyclic free-base porphyrin dimer or its inclusion complex with $\mathrm{C}_{60}$ as the
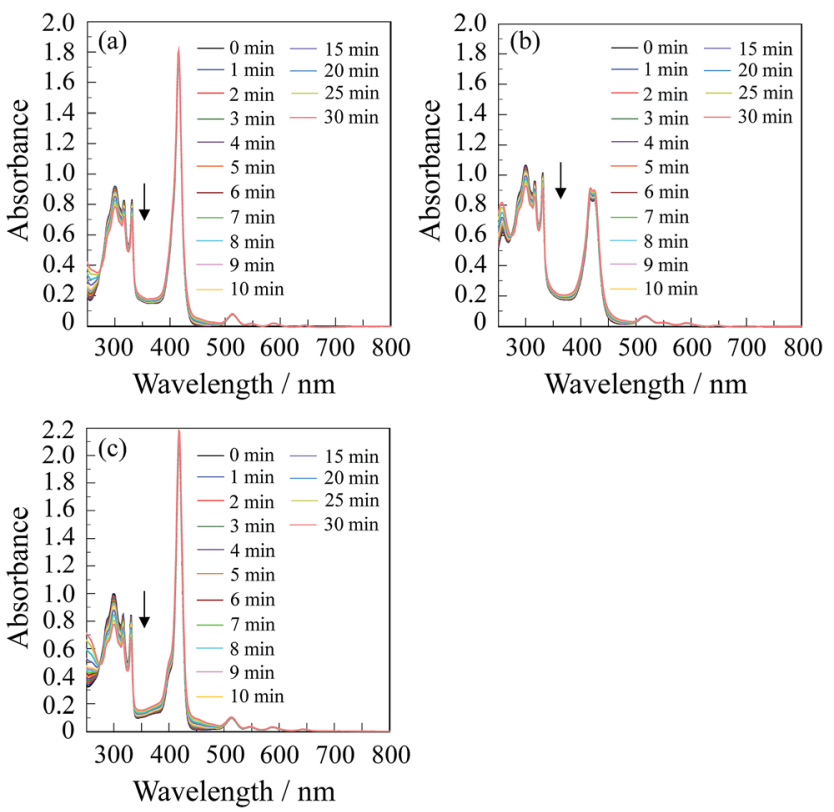

Fig. 6 Photoabsorption spectral changes for the photooxidation of $\operatorname{DHN}\left(1.0 \times 10^{-4} \mathrm{M}\right)$ using (a) CPD $\left(2.5 \times 10^{-6} \mathrm{M}\right),(\mathrm{b}) \mathrm{C}_{60} \subset \mathrm{CPD}(2.5 \times$ $\left.10^{-6} \mathrm{M}\right)$ and $(\mathrm{c}) \mathrm{H} 2 \mathrm{PyP}\left(5.0 \times 10^{-6} \mathrm{M}\right)$ as photosensitizer under photoirradiation with visible light $\left(>385 \mathrm{~nm}, 30 \mathrm{~mW} \mathrm{~cm}{ }^{-2}\right.$ ) in $\mathrm{CH}_{2} \mathrm{Cl}_{2}$ / $\mathrm{MeOH}(=1 / 1, v / v)$. 
photosensitizer (Table 1). Obviously, the higher $K_{\text {obs }}$ values of the cyclic free-base porphyrin dimer and its inclusion complex with $\mathrm{C}_{60}$ relative to $\mathrm{RB}$ (see Fig. $\mathrm{S} 2 \dagger$ ) are due to the contribution of the strong Soret band of the cyclic free-base porphyrin skeleton, although the $K_{\text {obs }}$ values of $\mathbf{C P D}$ and $\mathbf{C}_{\mathbf{6 0}} \subset \mathbf{C P D}$ are lower than that of $\mathbf{H 2 P y P}\left(9.5 \times 10^{-3} \mathrm{~min}^{-1}\right)$. It is worth noting here that the $K_{\text {obs }}$ value $\left(6.6 \times 10^{-3} \mathrm{~min}^{-1}\right)$ of $\mathbf{C P D}$ is greater than that $(5.8 \times$ $10^{-3} \mathrm{~min}^{-1}$ ) of $\mathbf{C}_{\mathbf{6 0}} \subset \mathbf{C P D}$. Therefore, this result demonstrates that CPD exhibits more efficient photosensitizing ability due to the effective ISC compared to $\mathbf{C}_{\mathbf{6 0}} \subset \mathbf{C P D}$.

In addition, we performed an electron paramagnetic resonance (EPR) method with 2,2,6,6-tetramethyl-4-piperidone (4oxo-TEMP) as the spin-trapping agent, which can react with ${ }^{1} \mathrm{O}_{2}$ to produce 4-oxo-TEMPO as a stable nitroxide radical. ${ }^{16}$ When the air-saturated solution containing $\mathbf{C P D}, \mathbf{C}_{60} \subset \mathbf{C P D}$ or H2PyP and 4-oxo-TEMP was irradiated with visible light (>385 nm, 30 $\mathrm{mW} \mathrm{cm} \mathrm{cm}^{-2}$ ) obtained by passage of xenon light through a $385 \mathrm{~nm}$ long path filter, for both the free-base porphyrin dimer and its inclusion complex with $\mathrm{C}_{60}$ as well as H2PyP the ESR spectra of 4-Oxo-TEMPO were clearly observed as a characteristic $1: 1: 1$ triplet (Fig. 7). Consequently, this work demonstrated that the cyclic free-base porphyrin dimer and its inclusion complex with $\mathrm{C}_{60}$ possess the ability to generate ${ }^{1} \mathrm{O}_{2}$ under visible light irradiation.
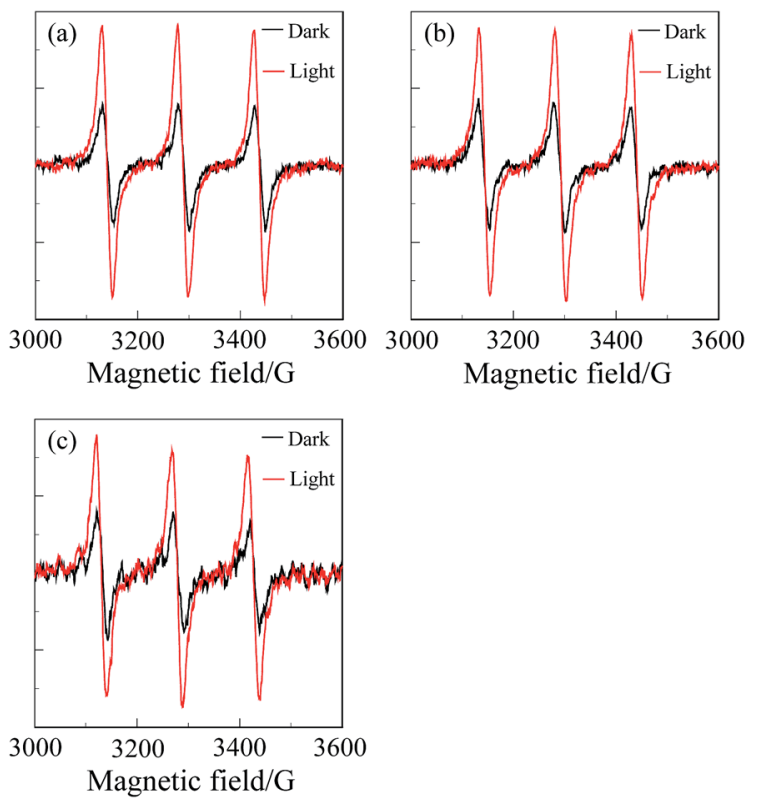

Fig. 7 The ESR spectra of 4-OxO-TEMPO which is formed by the reaction of 4-oxo-TEMP with ${ }^{1} \mathrm{O}_{2}$ which was generated by (a) CPD, (b) $\mathrm{C}_{60} \subset \mathrm{CPD}$ and (c) H2PyP under irradiation with visible light (temperature $298 \mathrm{~K}$, microwave power $1 \mathrm{~mW}$, microwave frequency 9.439 $\mathrm{GHz}$, and field modulation $0.2 \mathrm{mT}$ at $100 \mathrm{kHz}$ ). The air-saturated $\mathrm{CH}_{2} \mathrm{Cl}_{2}$ solution containing CPD $\left(2.5 \times 10^{-6} \mathrm{M}\right), \mathrm{C}_{60} \subset \mathrm{CPD}\left(2.5 \times 10^{-6}\right.$ M) or H2PyP $\left(5.0 \times 10^{-6} \mathrm{M}\right)$ as the photosensitizer and 4-oxo-TEMP $(50 \mathrm{mM})$ as the spin-trapping agent was irradiated with visible light (>385 nm, $30 \mathrm{~mW} \mathrm{~cm}^{-2}$ for $1 \mathrm{~h}$ ) obtained by passage of xenon light through a $385 \mathrm{~nm}$ long path filter, where $\mathrm{CH}_{2} \mathrm{Cl}_{2}$ as low polar solvent was used because it was difficult to obtain a clear ESR signal in polar solvent such as $\mathrm{CH}_{2} \mathrm{Cl}_{2} / \mathrm{MeOH}(=1 / 1$, v/v).

\section{Conclusions}

To investigate singlet oxygen $\left({ }^{1} \mathrm{O}_{2}\right)$ generation properties of cyclic free-base porphyrin dimer and its inclusion complex with fullerene $\mathrm{C}_{60}$, we evaluated the ${ }^{1} \mathrm{O}_{2}$ quantum yield $\left(\Phi_{\Delta}\right)$ and rate constant $\left(K_{\mathrm{obs}}\right)$ of ${ }^{1} \mathrm{O}_{2}$ generation for cyclic free-base porphyrin dimer CPD and its inclusion complex $\mathbf{C}_{60} \subset \mathbf{C P D}$ with $\mathrm{C}_{60}$. It was found that the $\Phi_{\Delta}$ value of $\mathbf{C}_{\mathbf{6 0}} \subset \mathbf{C P D}$ is lower than that of CPD. The lower $\Phi_{\Delta}$ value of the $\mathrm{C}_{60}$ inclusion complex would be attributed to the formation of charge-separated state $\mathbf{C}_{\mathbf{6 0}}{ }^{\cdot-}$ CPD $^{+}$, leading to low intersystem crossing (ISC) efficiency for the formation of triplet excited state ${ }^{3}(\mathbf{C P D})^{*}$, although it was expected that the formation of $\mathbf{C}_{\mathbf{6 0}}{ }^{-}{ }^{-} \mathbf{C P D}^{+}$is favorable for ${ }^{1} \mathrm{O}_{2}$ generation. Consequently, this work demonstrates that the cyclic free-base porphyrin dimer and its supramolecular complex with $\mathrm{C}_{60}$ possess the ability to generate ${ }^{1} \mathrm{O}_{2}$ under visible light irradiation.

\section{Experimental}

\section{Evaluation of ${ }^{1} \mathrm{O}_{2}$ quantum yield}

Quantum yield $\left(\Phi_{\Delta}\right)$ for singlet oxygen $\left({ }^{1} \mathrm{O}_{2}\right)$ generation by cyclic free-base porphyrin dimer CPD, its inclusion complex $\mathbf{C}_{60} \subset \mathbf{C P D}$ with fullerene $\mathrm{C}_{60}$ and $\mathbf{H} 2 \mathbf{P y P}$ in $\mathrm{CH}_{2} \mathrm{Cl}_{2} / \mathrm{MeOH}(=1 /$ $1, \mathrm{v} / \mathrm{v}$ ) was evaluated by monitoring the photoabsorption spectral change of the known ${ }^{1} \mathrm{O}_{2}$ scavenger 1,3-diphenylisobenzofuran (DPBF) accompanied by the reaction of DPBF with the generated ${ }^{1} \mathrm{O}_{2}$, that is, DPBF can trap ${ }^{1} \mathrm{O}_{2}$ through its photooxidation. $\mathrm{CH}_{2} \mathrm{Cl}_{2} / \mathrm{MeOH}$ was bubbled with air for $15 \mathrm{~min}$. The absorbance of DPBF was adjusted to around $1.0 \mathrm{in}$ air-saturated solvent. Concentration of $\mathbf{C P D}, \mathbf{C}_{\mathbf{6 0}} \subset \mathbf{C P D}$ or H2PyP was adjusted with an absorbance of $c a .0 .03$ at the irradiation wavelength $(509 \mathrm{~nm})$. The air-saturated solution containing the photosensitizer (CPD, $\mathbf{C}_{60} \subset \mathbf{C P D}$ or $\left.\mathbf{H 2 P y P}\right)$ and DPBF was irradiated with $509 \mathrm{~nm}\left(300 \mu \mathrm{W} \mathrm{cm}{ }^{-2}\right)$ obtained by passage of xenon light through monochromator. The photoabsorption spectral change of DPBF with the photoirradiation was monitored with an interval of $1 \mathrm{~min}$ up to $10 \mathrm{~min}$. The absorption band of DPBF at around $410 \mathrm{~nm}$ decreased with the increase in the photoirradiation time. The changes in optical density $(\triangle \mathrm{OD})$ of DPBF are plotted against the photoirradiation time, and the slope is used to estimate the $\Phi_{\Delta}$ values of $\mathbf{C P D}, \mathbf{C}_{60} \subset \mathbf{C P D}$ and $\mathbf{H 2 P y P}$. The $\Phi_{\Delta}$ values of CPD, $\mathbf{C}_{60} \subset \mathbf{C P D}$ and $\mathbf{H} 2$ PyP were estimated by the relative method using Rose Bengal (RB) $\left(\Phi_{\Delta}=0.80\right)$ in methanol as the standard. Therefore, the ${ }^{1} \Phi_{\Delta}$ values were calculated according to the following eqn (1):

$$
\Phi_{\Delta \mathrm{sam}}=\Phi_{\Delta \mathrm{ref}} \times\left[\left(m_{\mathrm{sam}} / m_{\mathrm{ref}}\right) \times\left(L_{\mathrm{ref}} / L_{\mathrm{sam}}\right)\right]
$$

where $\Phi_{\Delta \text { sam }}$ and $\Phi_{\Delta \text { ref }}$ are the ${ }^{1} \mathrm{O}_{2}$ quantum yield of photosensitizer (CPD, $\mathbf{C}_{60} \subset \mathbf{C P D}$ or $\mathbf{H 2 P y P}$ ) and $\mathrm{RB}$, respectively, $m_{\text {sam }}$ and $m_{\text {ref }}$ are the slope of the difference $(\Delta \mathrm{OD})$ in the change in the absorption maximum wavelength of DPBF (around $410 \mathrm{~nm}$ ) which are plotted against the photoirradiation time, $L_{\mathrm{sam}}$ and $L_{\mathrm{ref}}$ are the light harvesting 
efficiency, which is given by $L=1-10^{-A}$ (" $A$ " is the absorbance at the photoirradiation wavelength).

\section{Photosensitizing ability}

Photosensitizing ability of CPD, $\mathbf{C}_{60} \subset \mathbf{C P D}$ and $\mathbf{H} 2 \mathbf{P y P}$ in $\mathrm{CH}_{2} \mathrm{Cl}_{2} / \mathrm{MeOH}$ was evaluated by plotting the $\ln \left(C_{t} / C_{0}\right)$ against the photoirradiation time, where $C_{t}$ is a concentration of 1,5dihydroxynaphthalene (DHN) at the reaction time $(t)$ and $C_{0}$ is the initial concentration of DHN before photoirradiation. $\mathrm{CH}_{2} \mathrm{Cl}_{2} / \mathrm{MeOH}$ was bubbled with air for $15 \mathrm{~min}$. The airsaturated solution containing the photosensitizer $(2.5 \times$ $10^{-6} \mathbf{M}$ for $\mathbf{C P D}$ and $\mathbf{C}_{60} \subset \mathbf{C P D}, 5.0 \times 10^{-6} \mathrm{M}$ for $\mathbf{H 2 P y P}$ and $2.5 \times 10^{-6} \mathrm{M}$ for $\left.\mathrm{RB}\right)$ and $\mathrm{DHN}\left(1.0 \times 10^{-4} \mathrm{M}\right)$ was irradiated with visible light $\left(>385 \mathrm{~nm}, 30 \mathrm{~mW} \mathrm{~cm}^{-2}\right)$ obtained by passage of xenon light through a $385 \mathrm{~nm}$ long path filter. The photooxidation of DHN with the photoirradiation was monitored by following the decrease in the photoabsorption at around $300 \mathrm{~nm}$ with an interval of $1 \mathrm{~min}$ up to $10 \mathrm{~min}$ and then an interval of $5 \mathrm{~min}$ up to $30 \mathrm{~min}$. The concentration $\left(C_{t}\right)$ of DHN at the reaction time $(t)$ was calculated based on Lambert-Beer law $\left(A_{\mathrm{DPBF}}=\varepsilon c l\right)$. The $\ln \left(C_{t} / C_{0}\right)$ decreased almost linearly with the increase in the photoirradiation time due to the photooxidation of DHN, that is, the slope was used to estimate the rate constants $\left(K_{\mathrm{obs}}\right)$.

\section{${ }^{1} \mathrm{O}_{2}$ detection by EPR spin-trapping method with 4-oxo-TEMP}

The EPR spectra were recorded on a JEOL JES-RE1X spectrometer under the following experimental conditions: temperature $298 \mathrm{~K}$, microwave power $1 \mathrm{~mW}$, microwave frequency 9.439 $\mathrm{GHz}$, and field modulation $0.2 \mathrm{mT}$ at $100 \mathrm{kHz}$. The air-saturated $\mathrm{CH}_{2} \mathrm{Cl}_{2}$ solution containing CPD $\left(2.5 \times 10^{-6} \mathrm{M}\right), \mathbf{C}_{60} \subset \mathbf{C P D}(2.5$ $\left.\times 10^{-6} \mathrm{M}\right)$ or $\mathbf{H} 2 \mathbf{P y P}\left(5.0 \times 10^{-6} \mathrm{M}\right)$ as the photosensitizer and 4-Oxo-TEMP ( $50 \mathrm{mM})$ as the spin-trapping agent was irradiated with visible light (>385 $\mathrm{nm}, 30 \mathrm{~mW} \mathrm{~cm}^{-2}$ for $1 \mathrm{~h}$ ) obtained by passage of xenon light through a $385 \mathrm{~nm}$ long path filter. The ESR spectrum of 4-Oxo-TEMPO which is formed by the reaction of 4-oxo-TEMP with ${ }^{1} \mathrm{O}_{2}$, was clearly observed as a characteristic $1: 1: 1$ triplet (Fig. 7).

\section{Notes and references}

1 J. F. Lovell, T. W. B. Liu, J. Chen and G. Zheng, Chem. Rev., 2010, 110, 2839.

2 M. C. DeRosa and R. J. Crutchley, Coord. Chem. Rev., 2002, 233-234, 351.

3 M. Pawlicki, H. A. Collins, R. G. Denning and H. L. Anderson, Angew. Chem., Int. Ed., 2009, 48, 3244.

4 K. A. Leonard, M. I. Nelen, L. T. Anderson, S. L. Gibson, R. Hilf and M. R. Detty, J. Med. Chem., 1999, 42, 3942.

5 J. M. Dąbrowski and L. G. Arnaut, Photochem. Photobiol. Sci., 2015, 14, 1765.

6 T. Patrice, Photodynamic Therapy, Royal Society of Chemistry, 2003.

7 (a) R. Bonnett, Chem. Soc. Rev., 1995, 24, 19; (b) M. Ethirajan, Y. Chen, P. Joshi and R. K. Pandey, Chem. Soc. Rev., 2011, 40, 340.
8 (a) J. P. Belair, C. J. Ziegler, C. S. Rajesh and D. A. Modarelli, J. Phys. Chem. A, 2002, 106, 6445; (b) P. C. Lo, J. D. Huang, D. Y. Y. Cheng, E. Y. M. Chan, W. P. Fong, W. H. Ko and D. K. P. Ng, Chem.-Eur. J., 2004, 10, 4831; (c) A. Karotki, M. Khurana, J. R. Lepock and B. C. Wilson, Photochem. Photobiol., 2006, 82, 443; (d) L. Delanaye, M. A. Bahri, F. Tfibel, M.-P. Fontaine-Aupart, A. Mouithys-Mickalad, B. Heine, J. Piette and M. Hoebeke, Photochem. Photobiol. Sci., 2006, 5, 317; (e) M. Morone, L. Beverina, A. Abbotto, F. Silvestri, E. Collini, C. Ferrante, R. Bozio and G. A. Pagani, Org. Lett., 2006, 8, 2719; $(f)$ M. Khurana, H. A. Collins, A. Karotki, H. L. Anderson, D. T. Cramb and B. C. Wilson, Photochem. Photobiol., 2007, 84, 1441.

9 (a) A. P. Thomas, P. S. S. Babu, S. A. Nair, S. Ramakrishnan, D. Ramaiah, T. K. Chandrashekar, A. Srinivasan and M. R. Pillai, J. Med. Chem., 2012, 55, 5110; (b) K. Hirakawa, Y. Nishimura, T. Arai and S. Okazaki, J. Phys. Chem. B, 2013, 117, 13490; (c) H. Horiuchi, M. Hosaka, H. Mashio, M. Terata, S. Ishida, S. Kyushin, T. Okutsu, T. Takeuchi and H. Hiratsuka, Chem.-Eur. J., 2014, 20, 6054; (d) Q. Yu, E. M. Rodriguez, R. Naccache, P. Forgione, G. Lamoureux, F. Sanz-Rodriguez, D. Scheglman and J. A. Capobianco, Chem. Commun., 2014, 50, 12150; (e) D. Yao, V. Hugues, M. Blanchard-Desce, O. Mongin, C. O. Paul-Roth and F. Paul, New J. Chem., 2015, 39, 7730.

10 (a) M. Prein and W. Adam, Angew. Chem., Int. Ed., 2014, 53, 6938; (b) H. Shinmori, F. Kodaira, S. Matsugo, S. Kawabata and A. Osuka, Chem. Lett., 2005, 34, 322; (c) L. G. Arnaut, M. M. Pereira, J. M. Dąbrowski, E. F. F. Silva, F. A. Schaberle, A. R. Abreu, L. B. Rocha, M. M. Barsan, K. Urbańska, G. Stoche and C. M. A. Brett, Chem.-Eur. J., 2014, 20, 5346; (d) F. Hammerer, G. Garcia, S. Chen, F. Royer, S. Achelle, C. Fiorini-Debuisschert, M.-P. Telulade-Fichou and P. Maillard, J. Org. Chem., 2014, 79, 1406; (e) J. Schmitt, V. Heitz, A. Sour, F. Bolze, H. Ftouni, J.-F. Nicoud, L. Flamigni and B. Ventura, Angew. Chem., Int. Ed., 2015, 54, 169.

11 M. E. Milanesio, M. G. Alvarez, V. Rivarola, J. J. Silber and E. N. Durantini, Photochem. Photobiol., 2005, 81, 891.

12 (a) L. Huang, X. Yu, W. Wu and J. Zhao, Org. Lett., 2012, 14, 2594; (b) A. Kamkaew, S. H. Lim, H. B. Lee, L. V. Kiew, L. Y. Chung and K. Burgess, Chem. Soc. Rev., 2013, 42, 77; (c) L. Huang, X. Cui, B. Therrien and J. Zhao, Chem.-Eur. J., 2013, 19, 17472.

13 (a) H. Nobukuni, Y. Shimazaki, H. Uno, Y. Naruta, K. Okubo, T. Kojima, S. Fukuzumi, S. Seki, H. Sakai, T. Hasobe and F. Tani, Chem.-Eur. J., 2010, 16, 11611; (b) H. Nobukuni, T. Kamimura, H. Uno, Y. Shimazaki, Y. Naruta and F. Tani, Bull. Chem. Soc. Jpn., 2012, 85, 862; (c) K. Sakaguchi, T. Kamimura, H. Uno, S. Mori, S. Ozako, H. Nobukuni, M. Ishida and F. Tani, J. Org. Chem., 2014, 79, 2980; (d) T. Kamimura, K. Ohkubo, Y. Kawashima, H. Nobukuni, Y. Naruta, F. Tani and S. Fukuzumi, Chem. Sci., 2013, 4, 1451; (e) T. Kamimura, K. Ohkubo, Y. Kawashima, S. Ozako, K. Sakaguchi, S. Fukuzumi and F. Tani, J. Phys. Chem. C, 2015, 119, 25634; $(f)$ Y. Ooyama, 
K. Uenaka, T. Kamimura, S. Ozako, M. Kanda, T. Koide and F. Tani, RSC Adv., 2016, 6, 16150.

14 K. Golinick and A. Griesbeck, Tetrahedron, 1985, 41, 2057. 15 W. Wu, J. Sun, X. Cui and J. Zhao, J. Mater. Chem. C, 2013, 1, 4577.
16 (a) Y. Yamakoshi, N. Umezawa, A. Ryu, K. Arakane, N. Miyata, Y. Goda, T. Masumizu and T. Nagano, J. Am. Chem. Soc., 2003, 125, 12803; (b) S. Oriana, S. Aroua, J. O. B. Söllner, X.-J. Ma, Y. Iwamoto and Y. Yamakoshi, Chem. Commun., 2013, 49, 9302. 